\title{
Household food security and breast-feeding duration among Canadian Invit
}

\author{
Kathryn E Mclsaac ${ }^{1,2, *}$, David C Stock ${ }^{1,3}$ and Wendy Lou ${ }^{1}$ \\ 'Dalla Lana School of Public Health, University of Toronto, 30 Bond Street, Toronto, Ontario, Canada, M5B IW8: \\ ${ }^{2}$ Centre for Research on Inner City Health, St. Michael's Hospital, Toronto, Ontario, Canada: ${ }^{3}$ Toronto Rehabilitation \\ Institute, University Health Network, Toronto, Ontario, Canada
}

Submitted 26 August 2015: Final revision received 20 May 2016: Accepted 24 May 2016: First published online 28 July 2016

\begin{abstract}
Objective: There have been few studies investigating the association between food security and breast-feeding duration and none have been conducted among Canadian Inuit, a population disproportionately burdened with food insecurity. We evaluated the association between household food security and breast-feeding duration in Canadian Inuit children.

Design: Data were obtained from the Nunavut Inuit Child Health Survey, a population-based cross-sectional survey.

Setting: The Canadian Territory of Nunavut in 2007 and 2008.

Subjects: Caregivers of Inuit children aged 3-5 years. Participating children were randomly sampled from community medical centre lists.

Results: Out of 215 children, 147 lived in food-insecure households (68.4\%). Using restricted mean survival time models, we estimated that children in food-secure households were breast-fed for $16 \cdot 8$ (95\% CI 12.5, 21.2) months and children in food-insecure households were breast-fed for 21.4 (95\% CI 17.9, 24.8) months. In models adjusting for social class, traditional knowledge and child health, household food security was not associated with breast-feeding duration (hazard ratio $=0.82,95 \%$ CI $0.58,1 \cdot 14)$.

Conclusions: Our research does not support the hypothesis that children living in food-insecure households were breast-fed for a longer duration than children living in food-secure households. However, we found that more than $50 \%$ of mothers in food-insecure households continued breast-feeding well beyond 1 year. Many mothers in food-secure households also continued to breast-feed beyond 1 year. Given the high prevalence of food insecurity in Inuit communities, we need to ensure infants and their caregivers are being adequately nourished to support growth and breast-feeding, respectively.
\end{abstract}

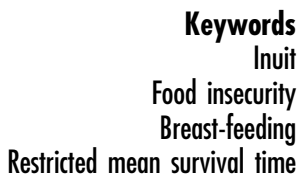

Food insecurity, namely failing to have 'access to sufficient, safe, nutritious food(s) to maintain a healthy and active life ${ }^{,(1)}$, is pervasive in Canadian Inuit communities: a 2007 survey estimated that $63 \%$ of Inuit households experienced food insecurity in the previous year, eight times greater than what has been estimated for the general Canadian population over the same period ${ }^{(2,3)}$. Despite this, not all of those who live in food-insecure households are food insecure themselves, and this is particularly true of young children. A survey of pre-school aged Canadian Inuit children and their caregivers found what while $70 \%$ of households with young children could be classified as food insecure, $56 \%$ of children living in these households could be classified as food insecure ${ }^{(4)}$. The observed discordance between household and childhood food insecurity is not surprising. Previous research has found adult caregivers struggling to afford nutritious foods attempt to shelter their children from food insecurity, making personal concessions like skipping meals or restricting energy intake ${ }^{(5-8)}$. One potential strategy that could also be utilized to keep children food secure is continued breast-feeding.

In the face of food insecurity, breast milk may be a nutritionally robust alternative, remaining a high fat, energy and protein source throughout maternal lactation $^{(9)}$. Breast milk may also be a cost-effective alternative: it has been estimated that toddlers aged 6 to 12 months can receive approximately half of their energy needs from breast milk and toddlers aged 12 to 23 months can receive approximately $35-40 \%$ of their daily energy intake from breast milk $^{(10,11)}$. Globally, public health organizations recommend infants receive exclusive breast-feeding to 
6 months and continued breast-feeding in complement with solid, semi-solid or soft foods up to 2 years of age and beyond $^{(12-14)}$. The Canadian Maternity Experiences Survey (2006) reported that just over half (53\%) of Canadian infants were still being breast-fed at 6 months of age ${ }^{(15)}$, and we recently estimated more than $60 \%$ of Inuit children who were raised by a biological mother were still being breast-fed at 6 months of age ${ }^{(16)}$. Among Canadian Inuit, factors associated with continued breast-feeding at and beyond 6 months have not been identified, and food insecurity may be one such factor.

There have been few studies examining the association between food insecurity and breast-feeding practices and most of this work has been conducted in developing countries $^{(17-20)}$. Moreover, the findings have been inconsistent: differences in study populations, definitions of food security and control for confounding could be driving these inconsistencies. Previous research has examined how food insecurity impacted breast-feeding initiation ${ }^{(21)}$ and exclusive breast-feeding at 6 months ${ }^{(16)}$ among Canadian Inuit infants, but failed to find sufficient evidence to support associations. However, existing research suggests food insecurity may have the greatest impact on breast-feeding duration beyond the infant's first 6 months of life and there has been no work in this regard in Inuit communities ${ }^{(19,20)}$.

Understanding if food security affects overall breastfeeding duration would be of public health importance for this disproportionately burdened population. Our study sought to examine the association between household food security and the duration of breast-feeding in a population of Canadian Inuit children. We hypothesized that food-insecure homes would breast-feed their children for longer durations, in an attempt to shelter them from food insecurity.

\section{Methods}

\section{Study design and sample}

The Nunavut Inuit Child Health Survey was a populationbased, cross-sectional survey of Inuit children conducted in the Canadian Territory of Nunavut between July and November, 2007 and 2008. The survey was designed to capture the health profiles, demographic profiles and home environments of pre-school aged Inuit children (aged 3 to 5 years old) living in Nunavut and used a community-based participatory research model. The survey received ethical approval from the McGill University Research Ethics Board and we received supplementary ethical approval for the current analyses from the University of Toronto's Research Ethics Board.

Nunavut is Canada's north-eastern most territory; it has the largest land mass of any Canadian territory or province and has the lowest population density ${ }^{(22)}$. It is also home to almost half (46\%) of Canada's Inuit population ${ }^{(22)}$.
In 2011, approximately 32000 Canadians lived in one of Nunavut's twenty-five communities and $85 \%$ of these self-identified as Inuit ${ }^{(22)}$.

Sixteen Nunavut communities were selected to participate in the Nunavut Inuit Child Health Survey; including the remaining nine communities was not feasible due to the small number of inhabitants relative to the cost of northern travel. Children living in one of the sixteen selected communities were randomly sampled from lists provided by the community health centres and, as the sole source of health care in these communities, these lists were expected to be free of coverage errors. More information about the sampling strategy and the generation of sampling weights is provided elsewhere ${ }^{(4,21)}$.

Once a child was randomly selected from the community centre lists (i.e. the sampling frame), a member of the research team contacted the primary caregiver and asked them to view an informational DVD. This DVD was used to help caregivers provide informed consent. The primary caregiver was defined as the person most responsible for the child's care. After watching the DVD, those caregivers consenting to participate were invited to a community site, usually a health centre, where an English- or Inuk-speaking member of the research team orally administered a series of questionnaires. Interviews typically occurred within two weeks of initial contact with the child's primary caregiver.

Because our prior research has demonstrated food insecurity was not associated with beginning breastfeeding ${ }^{(21)}$, we restricted the present study to children who received some breast-feeding as infants. We excluded children who did not initiate breast-feeding because we were specifically interested in knowing, among those mothers who already began breast-feeding, whether food security played an instrumental role in their decision to continue breast-feeding.

\section{Measures of interest}

The main outcome of interest was time to cessation of breast-feeding. All respondents were asked to complete the open-ended question, 'How many months was your child breast-fed or fed breast milk, including mixed feedings (i.e. formula, food, cows' milk)?' In the analyses, we grouped the reported breast-feeding duration into two-month intervals. We elected to use two-month intervals to avoid inflated effect sizes resulting from artificial accuracy of recalled breast-feeding duration. Studies suggest that at least $80 \%$ of mothers are able to recall duration of breast-feeding fairly accurately within two months and this may drop to $60 \%$ for one-month increments ${ }^{(23,24)}$.

The primary exposure was household food insecurity. This was measured using a modified version of the US Department of Agriculture's eighteen-item Food Security Module $^{(25)}$, a tool that has been validated in a variety of populations around the world ${ }^{(26-28)}$. The Food Security 
Module is designed to measure the household-level economic and social condition of limited or uncertain access to adequate food. It asks questions pertaining to individuals' and their households' experience with food insecurity in the previous year and includes questions such as 'The foods that we bought just didn't last'. Modifications to the language used in the scale were made to increase acceptability and applicability in an Inuit population. These modifications are described elsewhere and included replacing the response options 'always true', 'sometimes true' or 'never true' to 'often', 'sometimes' or 'never' ${ }^{(29)}$. Like the original scale, ten questions on the modified inventory pertained to adult food security and eight pertained to child food security. The adult and child scales were scored separately in accordance with Health Canada's recommendations ${ }^{(30)}$ : adults and children scoring between 0 and 1 were classified as food secure; adults scoring between 2 and 5 and children scoring between 2 and 4 were classified as moderately food insecure; adults scoring 6 or more and children scoring 5 or more were classified as severely food insecure ${ }^{(30)}$. These separate child and adult scores were then used to generate an overall household food security classification. For the purposes of the present analyses, we collapsed together households that would have been classified as being 'moderate' and 'severe' food insecure if we had used Health Canada's recommendations ${ }^{(30)}$. Specifically, if adults and children were both food secure, the household was classified as food secure; if adults or children or both were food insecure, the household was classified as food insecure ${ }^{(30)}$.

In effort to obtain the most accurate estimate of the association between food security and breast-feeding duration, we included other covariates in our analyses. We divided these into three categories: (i) indicators of socio-economic position; (ii) indicators of infant and child health; and (iii) indicators of Inuit traditional knowledge.

Lower socio-economic position has been associated with shorter duration of breast-feeding ${ }^{(31,32)}$ and greater food insecurity ${ }^{(3,33,34)}$. Three self-reported indicators were used to measure socio-economic position: if a household was receiving income support, if the home was privately owned and if the home had mould or was in need of major repair. Other indicators of socio-economic position, like occupation, education and household income, were not collected in the Nunavut Inuit Child Health Survey. Indicators of socio-economic position were dichotomized as yes/no in our analyses.

Three indicators of infant and child health were used: the caregiver's perception of the child's health, infant birth weight and child's BMI (centile). Caregiver's perception of health was measured on a five-point Likert scale with response options ranging from 'excellent' to 'poor'. Children whose caregivers indicated they had excellent or very good health were classified as having 'excellent or very good' self-rated health; others were classified as having 'suboptimal' self-rated health in analyses. In terms of infant birth weight, infants were classified as either being born low birth weight $(<2500 \mathrm{~g})$ or not. Poor infant health has been associated with earlier cessation of breastfeeding and also with food insecurity ${ }^{(35)}$.

Finally, two indicators of Inuit traditional knowledge were used: speaking Inuit dialects at home and hunting for country food. Historically, it has been reported that Inuit women practised breast-feeding for up to 3 years ${ }^{(36)}$; it is possible that a longer duration of breast-feeding could exist in the present day among women who are more engaged with Inuit culture. Similarly, having a hunter in the household to provide country food has been shown to mitigate food insecurity in Canada's north ${ }^{(2)}$.

\section{Statistical analyses}

Analyses were conducted using the statistical software packages SAS version 9.4 and Stata version 13. Both software packages offer procedures to account for the random sampling strategy of the Nunavut Inuit Child Health Survey, to make population-level inferences using sampling weights ${ }^{(37)}$ and to appropriately estimate variances for sub-populations ${ }^{(37,38)}$. We used a complete case analysis strategy, wherein only those with complete data on all indicators of interest were included. All statistical inferences were two-sided and confidence limits that did not cross 1 were considered statistically significant.

We performed descriptive analyses, exploring how demographic characteristics, socio-economic position, infant health and measures of traditional knowledge varied by household food security. Kaplan-Meier curves, both ignoring and taking into account sample weighting, were used to estimate the probability of continued breastfeeding across household food security categories. The association between food security and breast-feeding duration was evaluated using two survival models: Cox and flexible parametric proportional hazards models. We used the latter to estimate restricted mean time to breastfeeding cessation (i.e. restricted mean survival time) across household food-secure and food-insecure respondents.

Flexible parametric proportional hazards were estimated using the stpm2 Stata program ${ }^{(39)}$. These models first compute the survival function (i.e. $S(t)$ ) after fitting a Cox proportional hazards model, which is used to estimate a log cumulative hazard function. The log cumulative hazard function is smoothed on the log scale and is comprised of restricted cubic splines that allow for flexible parameterization over time ${ }^{(40)}$. These models were used to estimate the relative instantaneous hazard of discontinuing breast-feeding by household food security. All infants who were still being breast-fed at the time of the survey or beyond 60 months of age were right censored. Because these analyses were based on a cross-section of data reported at 60 months, no observations were censored due to loss to follow-up.

We fit four sets of nested models in succession. In our first model, we examined the crude association between 
food insecurity and breast-feeding; the second model adjusted for socio-economic position; the third model adjusted for infant health characteristics; the fourth and final model adjusted for Inuit traditional knowledge. Departures from proportionality over time were assessed for all covariates using statistical tests and visual inspection $^{(41)}$. For Cox models, covariates exhibiting potentially disproportionate effects over time were modelled as stratification variables rather than independent effects ${ }^{(41)}$. For flexible parametric models, these variables were allowed to have partitioned parameter effects over time (i.e. time-varying coefficients) for optimal adjustment of potential confounding. Standard errors for the restricted means were computed using bootstrapping methods.

\section{Results}

There were 537 caregivers who were successfully contacted and asked to participate in the Nunavut Inuit Child Health Survey, and 388 completed the questionnaires (response rate of $72 \cdot 2 \%$ ). Of these, 263 began breast-feeding and were eligible for the current analyses. We excluded those missing information on breast-feeding duration ( $n$ 20), household food security ( $n$ 7) and other covariates ( $n$ 21); in that order. There were 215 participants who remained and were included in the analyses.

Overall, we found that sixty-eight (31.6\%) households were food secure and 147 (68.4\%) were food insecure. Table 1 shows the characteristics of study respondents by household food security classification. Those of lower socio-economic position were significantly more likely to report household food insecurity. For example, 26\% of food-secure households and 53\% of food-insecure households reported receiving income support in the previous month $(P<0 \cdot 001)$. There were no differences in children's health indicators by food insecurity, or in traditional knowledge by food insecurity.

The estimated restricted mean time to breast-feeding cessation for food-secure and food-insecure households was 16.8 (95\% CI 12.5, 21.2) months and 21.4 (95\% CI $17 \cdot 9,24 \cdot 8)$ months, respectively, ignoring sample weights; and $16.0(95 \%$ CI 11.6, 20.3) months and 19.8 (95\% CI $16 \cdot 3,23 \cdot 2)$, respectively, with sample weights. Figure 1 shows the unweighted Kaplan-Meier curves estimating the probability of continued breast-feeding over time by household food security. These graphs indicate that $50 \%$ of children in food-insecure households were breast-fed for 12 months or more and $50 \%$ of children in food-secure households were breast-fed for 8 months or more, although these differences were not statistically significant (log-rank test, $P=0 \cdot 09$ ). Weighted curves were similar (not shown).

Table 2 presents the instantaneous hazard of discontinuing breast-feeding according to household food security status. Estimates from both Cox and flexible
Table 1 Demographic characteristics of the study sample, by food security status; Nunavut Inuit Child Health Survey, 2007-2008 (n 215)

\begin{tabular}{|c|c|c|c|c|}
\hline \multirow[b]{2}{*}{ Characteristic } & \multicolumn{2}{|c|}{$\begin{array}{l}\text { Food secure } \\
\qquad(n 68)\end{array}$} & \multicolumn{2}{|c|}{$\begin{array}{l}\text { Food insecure } \\
(n 147)\end{array}$} \\
\hline & $\begin{array}{l}n \text { or } \\
\text { mean }\end{array}$ & $\begin{array}{l}\% \text { or } \\
\text { SD }\end{array}$ & $\begin{array}{l}n \text { or } \\
\text { mean }\end{array}$ & $\begin{array}{l}\% \text { or } \\
\text { SD }\end{array}$ \\
\hline \multicolumn{5}{|l|}{ Caregiver demographics } \\
\hline \multicolumn{5}{|l|}{ Sex† } \\
\hline Male & 7 & 11 & 13 & 9 \\
\hline Female & 59 & 89 & 133 & 91 \\
\hline \multicolumn{5}{|l|}{ Relationship to child $†$} \\
\hline Biological parent & 61 & 93 & 129 & 88 \\
\hline Other & 5 & 7 & 17 & 12 \\
\hline \multicolumn{5}{|l|}{ Child demographics } \\
\hline $\begin{array}{l}\text { Age (years), mean and SD } \\
\text { Sex }\end{array}$ & 4.0 & 0.8 & 3.8 & 0.8 \\
\hline Male & 29 & 43 & 71 & 48 \\
\hline Female & 39 & 57 & 76 & 52 \\
\hline \multicolumn{5}{|l|}{ Socio-economic position } \\
\hline \multicolumn{5}{|l|}{ Receives income support*** } \\
\hline Yes & 18 & 26 & 78 & 53 \\
\hline No & 50 & 74 & 69 & 47 \\
\hline \multicolumn{5}{|l|}{ Lives in public housing ${ }^{\star \star \star}$} \\
\hline Yes & 31 & 46 & 121 & 82 \\
\hline No & 37 & 54 & 26 & 18 \\
\hline \multicolumn{5}{|l|}{ House needs repairs ${ }^{\star \star *}$} \\
\hline Yes & 20 & 29 & 71 & 48 \\
\hline No & 48 & 71 & 76 & 52 \\
\hline \multicolumn{5}{|l|}{ Childhood health status } \\
\hline $\begin{array}{l}\text { BMI (centile), mean and SD } \\
\text { Birth weight }\end{array}$ & 89.6 & 14 & 88.0 & 16 \\
\hline Low birth weight & 2 & 3 & 12 & 8 \\
\hline Healthy birth weight & 66 & 97 & 135 & 92 \\
\hline \multicolumn{5}{|l|}{ Self-rated health } \\
\hline Suboptimal & 5 & 7 & 10 & 7 \\
\hline Very good, excellent & 63 & 93 & 137 & 93 \\
\hline \multicolumn{5}{|l|}{ Traditional knowledge } \\
\hline \multicolumn{5}{|l|}{ Having a hunter in house } \\
\hline Yes & 49 & 72 & 105 & 71 \\
\hline No & 19 & 28 & 42 & 29 \\
\hline
\end{tabular}

${ }^{\star * \star} P<0.001$.

†Characteristics reported for 212 respondents; three were missing, two food secure and one moderately food secure.

parametric proportional hazards models were not materially different, suggesting an approximate $20 \%$ reduced hazard of breast-feeding cessation among food-insecure households. However, this effect was not statistically significant because all of our $95 \%$ confidence limits crossed the null value of 1 . Furthermore, there was no indication of confounding by socio-economic position, child health or traditional knowledge factors.

\section{Discussion}

We used a population-based representative sample to explore the association between food insecurity and breast-feeding duration in Canadian Inuit. Although our point estimates suggest that infants and children who lived in food-insecure households were breast-fed for a longer duration than children who lived in food-secure 


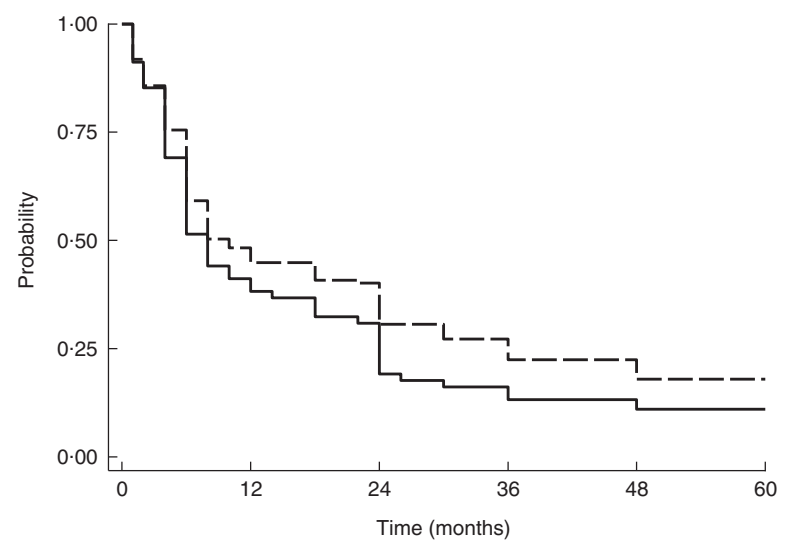

Fig. 1 Sample unweighted Kaplan-Meier functions illustrating the crude probability of continued breast-feeding by household food security status (- $\longrightarrow$, food secure; ----- , food insecure); Nunavut Inuit Child Health Survey, 2007-2008 (n 215)

households, we did not find sufficient evidence to suggest these differences were statistically significant. This supports similar null findings reported in Bangladesh ${ }^{(18)}$; but is inconsistent with research in low-income American women and Brazilian women that reports food insecurity is associated with longer duration of breast-feeding ${ }^{(19,20)}$.

The high prevalence of food insecurity in Canadian Inuit communities is concerning although not surprising: policy makers, community members and scholars have all spoken of this pervasive and troubling concern ${ }^{(42,43)}$. Although the prevalence of food insecurity has been reported previously by the Inuit Health Survey ${ }^{(2,4,33)}$, our research is the first to consider if food insecurity may impact breast-feeding decisions in Canada's north. From a public health standpoint, receiving adequate nutrition in the first 2 years of life is essential to prevent growth faltering and persistent stunting throughout the life course $^{(44,45)}$. Recent research in Nunavik, an Inuitinhabited region in Canada, estimated that food-insecure Inuit children were, on average, $2 \mathrm{~cm}$ shorter than their food-secure counterparts at ages 8 to 15 years ${ }^{(46)}$; this may speak to inadequate nutrition early in the life course. We did not have information on the diets of study participants during their first 2 years of life, but such information is pertinent. Although breast milk can provide sufficient nutrition in the first 6 months of life (especially in concert with a daily vitamin D supplement (10 $\mu \mathrm{g} / 400 \mathrm{IU})$ ), additional, complementary foods are required thereafter ${ }^{(10,13)}$ : breast-feeding alone cannot protect a child from childhood food insecurity.

It is also important to note that women who practise breast-feeding require additional energy to support lactation. To maintain current weight, a breast-feeding women requires an extra $2092 \mathrm{~kJ}$ ( $500 \mathrm{kcal}$ ) per day between 6 and 8 months postpartum and an extra $1464 \mathrm{~kJ}$ (350 kcal) per day at 9 months postpartum and beyond ${ }^{(47)}$. We estimate that many Inuit women living in food-insecure households were breast-feeding for extended durations: $50 \%$ of food-insecure mothers breast-fed their infants for 12 months or more. It is unclear if these women received the nutrition they needed to support lactation; and as such they may have been compromising their own health. Anthropometric measures for the biological mother (e.g. height, weight) were available only for biological mothers who participated in the Nunavut Health Survey, a concurrently running health survey of Inuit adults. This applied to less than $25 \%$ of the children in our study, i.e. fewer than $25 \%$ had maternal height and weight on record.

That said, recent research suggests that Inuit women of childbearing age have adequate, if not excess, energy intake but that many of the foods consumed are of poor quality $^{(48)}$. As a result, many Inuit women of childbearing age have substantial nutrient deficiencies ${ }^{(48)}$. Breast milk's nutritional composition is directly affected by the maternal diet; even if women in our study had sufficient energy to breast-feed, the micronutrients they were passing to their child may be at suboptimal levels ${ }^{(49)}$.

\section{Limitations}

Our research should be interpreted with the following limitations in mind. First, we used cross-sectional survey data to obtain information on food insecurity in the year prior to data collection. Children were aged 3-5 years at the time of the survey and many had stopped breastfeeding. These analyses assume that food insecurity was static since the child's birth, which may or may not be true. To truly understand the relationship between food insecurity and breast-feeding, prospective data should be collected starting before the infant is born. Such prospective data can also help inform if household food availability and scarcity has affected growth trajectories in Inuit children in Canada. A second and related limitation, children and their caregivers had to be alive and willing to participate in the cross-sectional survey. Because food insecurity is associated with increased morbidity and mortality $^{(35)}$, our sample may include healthy foodinsecure survivors. Such healthiness may be related to breast-feeding, which has been shown to mitigate infant morbidity and mortality ${ }^{(50)}$. As a result, our sample drawn at 3-5 years of age may have over-selected food-insecure children who were breast-fed for longer durations than we would have obtained had we drawn our sample shortly after birth. There are also concerns with measurement error. Responses were from the child's primary caregiver at the time of the survey: this may have been the biological mother but it could also have been the biological father, an adoptive parent or a grandparent. Recall of breast-feeding duration for these other caregiver groups is not certain. It should also be noted that the survey measured household food insecurity and we cannot be certain that the child was food insecure. Finally, our failure to find sufficient evidence to support an association between food insecurity and 
breast-feeding duration may have been due to inadequate study power; the Nunavut Inuit Child Health Survey was powered to determine the prevalence of iron-deficiency anaemia $( \pm 5 \%)$ and not to study the association between food insecurity and breast-feeding duration. Indeed, our confidence interval suggests that food-insecure homes could have as low as a $50 \%$ reduced hazard of breast-feeding cessation or as high as a $15 \%$ increased hazard of breastfeeding cessation compared with food-secure homes.

\section{Conclusion}

Household food insecurity was pervasive among Inuit households, although it did not appear to be associated with breast-feeding duration: we did not find an association between food insecurity and breast-feeding duration in our population-based sample of Canadian Inuit. Programmes and services that can address the nutrition of vulnerable women and children in food-insecure northern Canadian communities are needed.

\section{Acknowledgements}

Acknowledgements: The authors are grateful for the guidance and feedback from all members of the Inuit Health Survey Steering Committee, including Dr Hope Weiler. Financial support: K.E.M. is a Canadian Institutes for Health Research (CIHR) Strategic Training Fellow in the ACHIEVE Research Partnership: Action for Health Equity Interventions. K.E.M. gratefully acknowledges the support of the CIHR (grant number 96566) and the Ontario Ministry of Health and Long-Term Care. The funders had no role in the design, analysis or writing of this article. Disclaimer: The views expressed in this publication are the views of the authors and do not necessarily reflect the views of the Ontario Ministry of Health and Long-Term Care. Conflict of interest: None. Authorship: K.E.M. conceived the research question, designed the study, interpreted the data and wrote the first draft of the manuscript. D.C.S. conducted the data analysis, interpreted the data and revised the drafted manuscript. W.L. created the data analysis plan, interpreted the data and revised the drafted manuscript. Ethics of human subject participation: Ethical approval for this study was granted from the Institutional Review Board at the McGill Faculty of Medicine and approval for these secondary analyses was granted from the University of Toronto's Research Ethics Board.

\section{References}

1. Food and Agriculture Organization of the United Nations (1996) Rome Declaration on World Food Summit Plan of Action. Rome: FAO; available at http://www.fao.org/doc rep/003/w3613e/w3613e00.HTM 
2. Huet C, Rosol R \& Egeland G (2012) The prevalence of food insecurity is high and the diet quiality poor in Inuit communities. J Nutr 142, 541-547.

3. Health Canada (2012) Household food insecurity in Canada in 2007-2008: key statistics and graphics. http://www.hc-sc. gc.ca/fn-an/surveill/nutrition/commun/insecurit/key-stats-cles2007-2008-eng.php (accessed January 2014).

4. Egeland GM, Pacey A, Cao Z et al. (2010) Food insecurity among Inuit preschoolers: Nunavut Inuit Child Health Survey, 2007-2008. CMAJ 182, 243-248.

5. Partyka B, Whiting S, Grunerud D et al. (2010) Infant nutrition in Saskatoon: barriers to infant food security. Can J Diet Pract Res 71, 79-84.

6. Hamelin A-M, Beaudry M \& Habicht J-P (2002) Characterization of household food insecurity in Quebec: food and feelings. Soc Sci Med 54, 119-132.

7. Ford JD \& Beaumier M (2011) Feeding the family during times of stress: experience and determinants of food insecurity in an Inuit community. Geogr J 177, 44-61.

8. Beaumier M \& Ford JD (2010) Food insecurity among Inuit women exacerbated by socio-economic stresses and climate change. Can J Public Health 101, 196-201.

9. Dewey KG (2002) Guiding Principles for complementary feeding of the breastfed child. http://www.who.int/nutrition/ publications/guiding_principles_compfeeding_breastfed.pdf (accessed February 2013).

10. Infant Feeding Joint Working Group (2014) Nutrition for healthy term infants: recommendations from six to 24 months: a joint statement of Health Canada, Canadian Paediatric Society, Dietitians of Canada, and Breastfeeding Committee for Canada. http://www.hc-sc.gc.ca/fn-an/ nutrition/infant-nourisson/recom/recom-6-24-months-6-24mois-eng.php (accessed January 2015).

11. Dewey KG \& Brown KH (2003) Update on technical issues concerning complementary feeding of young children in developing countries and implications for intervention programs. Food Nutr Bull 24, 5-28.

12. World Health Organization (2001) The World Health Organization's infant feeding recommendation. http:// www.who.int/nutrition/topics/infantfeeding_recommenda tion/en/index.html (accessed June 2009).

13. Infant Feeding Joint Working Group (2012) Nutrition for healthy term infants: recommendations from birth to six months: a joint statement of Health Canada, Canadian Paediatric Society, Dietitians of Canada, and Breastfeeding Committee for Canada. http://www.hc-sc.gc.ca/fn-an/nutrition/infant-nourisson/ recom/index-eng.php (accessed January 2015).

14. American Academy of Pediatrics (2012) Breastfeeding and the use of human milk. Pediatrics 129, e827-e841.

15. Chalmers B, Levitt C, Heaman M et al. (2009) Breastfeeding rates and hospital breastfeeding practices in Canada: a national survey of women. Birth 36, 122-132.

16. McIsaac K, Lou W, Sellen D et al. (2014) Exclusive breastfeeding among Canadian inuit: results from the Nunavut Inuit Child Health Survey. J Hum Lact 30, 229-241.

17. Gross RS, Mendelsohn AL, Fierman AH et al. (2012) Food insecurity and obesogenic maternal infant feeding styles and practices in low-income families. Pediatrics 130, 254-261.

18. Saha KK, Frongillo EA, Alam DS et al. (2008) Household food security is associated with infant feeding practices in rural Bangladesh. J Nutr 138, 1383-1390.

19. Brown LS, Colchamiro R, Edelstein S et al. (2013) Effect of prenatal and postpartum food security status on breastfeeding initiation and duration in Massachusetts WIC participants 2001-2009. FASEB J 27, 1 Suppl., 1054.13.

20. Gomes GP \& Gubert MB (2012) Breastfeeding in children under 2 years old and household food and nutrition security status. J Pediatr (Rio J) 88, 279-282.

21. McIsaac K, Sellen D, Lou W et al. (2015) Prevalence and characteristics associated with breastfeeding initiation among Canadian Inuit from the 2007-2008 Nunavut Inuit Child Health Survey. Matern Child Health J 19, 2003-2011.

22. Statistics Canada (2013) Aboriginal Peoples in Canada: First Nations People, Metis and Inuit, Vol. 99-011-x2011001. Ottawa, ON: Minister of Industry.

23. Li R, Scanlon KS \& Serdula MK (2005) The validity and reliability of maternal recall of breastfeeding practice. Nutr Rev 63, 103-110.

24. Natland ST, Andersen LF, Nilsen TIL et al. (2012) Maternal recall of breastfeeding duration twenty years after delivery. BMC Med Res Methodol 12, 179.

25. Bickel G, Nord M, Prince C et al. (2000) Measuring food security in the United States. http://www.fns.usda.gov/fsec/ files/fsguide.pdf (accessed May 2014).

26. Gulliford MC, Nunes C \& Rocke B (2006) The 18 Household Food Security Survey items provide valid food security classifications for adults and children in the Caribbean. BMC Public Health 6, 26.

27. Frongillo EA (1999) Validation of measures of food insecurity and hunger. J Nutr 129, 2S Suppl., 506S-509S.

28. Pérez-Escamilla R, Segall-Corrêa AM, Maranha LK et al. (2004) An adapted version of the US Department of Agriculture Food Insecurity module is a valid tool for assessing household food insecurity in Campinas, Brazil. J Nutr 134, $1923-1928$.

29. Lawn J \& Harvey D; Dialogos Educational Consultants Inc. (2003) Nutrition and food security in Kugaaruk, Nunavut: baseline survey for the Food Mail pilot project. http:// dsp-psd.pwgsc.gc.ca/Collection/R2-265-2003E.pdf (accessed March 2009).

30. Health Canada (2007) Canadian Community Health Survey, Cycle 2.2, Nutrition (2004): Income-related Household Food Security in Canada. Ottawa, ON: Health Canada.

31. McDonald SD, Pullenayegum E, Chapman B et al. (2012) Prevalence and predictors of exclusive breastfeeding at hospital discharge. Obstet Gynecol 119, 1171-1179.

32. Kelly Y \& Watt R (2005) Breast-feeding initiation and exclusive duration at 6 months by social class - results from the Millennium Cohort Study. Public Health Nutr 8, 417-421.

33. Egeland GM, Williamson-Bathory L, Johnson-Down L et al. (2011) Traditional food and monetary access to marketfood: correlates of food insecurity among Inuit preschoolers. Int J Circumpolar Health 70, 373-383.

34. Nord M \& Hopwood H (2008) A Comparison of Household Food Security in Canada and the United States. Washington, DC: US Department of Agriculture, Economic Research Service.

35. Cook JT, Frank DA, Berkowitz C et al. (2004) Food insecurity is associated with adverse health outcomes among human infants and toddlers. J Nutr 134, 1432-1438.

36. Pauktuutit Inuit Women of Canada (2006) The Inuit way: a guide to Inuit culture. http://www.uqar.ca/files/boreas/ inuitway_e.pdf (accessed May 2014).

37. SAS Institute, Inc. (2008) Introduction to Survey Sampling and Analysis Procedures. SAS/STAT 9.2 User's Guide. Cary, NC: SAS Institute, Inc.

38. Graubard B \& Korn E (1996) Survey inference for subpopulations. Am J Epidemiol 144, 102-106.

39. Royston P \& Parmar MK (2011) The use of restricted mean survival time to estimate the treatment effect in randomized clinical trials when the proportional hazards assumption is in doubt. Stat Med 30, 2409-2421.

40. Lambert PC \& Royston P (2009) Further development of flexible parametric models for survival analysis. Stata J 9, 265-290.

41. Therneau TM \& Grambsch PM (2000) Modeling Survival Data: Extending the Cox Model. New York: Springer Science \& Business Media.

42. Council of Canadian Academies (2014) Aboriginal Food Security in Northern Canada: An Assessment of the State of Knowledge. Ottawa, ON: Council of Canadian Academies. 
43. Health Canada (2012) First Nations and Inuit Health Strategic Plan: A Shared Path to Improved Health. Ottawa, ON: Health Canada.

44. Shrimpton R, Victora CG, de Onis M et al. (2001) Worldwide timing of growth faltering: implications for nutritional interventions. Pediatrics 107, e75.

45. Black RE, Allen LH, Bhutta ZA et al. (2008) Maternal and child undernutrition: global and regional exposures and health consequences. Lancet 371, 243-260.

46. Pirkle CM, Lucas M, Dallaire R et al. (2014) Food insecurity and nutritional biomarkers in relation to stature in Inuit children from Nunavik. Can J Public Health 105, e233-e238.
47. Dewey KG (1997) Energy and protein requirements during lactation. Annu Rev Nutr 17, 19-36.

48. Schaefer SE, Erber E, Trzaskos JP et al. (2011) Sources of food affect dietary adequacy of inuit women of childbearing age in Arctic Canada. J Health Popul Nutr 29, 454-464.

49. Allen L (1994) Maternal micronutrient malnutrition: effects on breast milk and infant nutrition, and priorities for intervention. SCN News 11, 21-24.

50. Ip S, Chung M, Raman G et al. (2009) A summary of the Agency for Healthcare Research and Quality's evidence report on breastfeeding in developed countries. Breastfeed Med 4, 17-30. 